\title{
TETANUS IMMUNISATION IN THE BRITISH ARMY
}

The Armed Services have played an important role in the development of prophylactic immunisation against tetanus. Passive immunisation using tetanus antitoxin produced in horses was introduced on a large scale in the war of 1914-18 as a part of the prophylactic treatment of all lacerated wounds, reducing the incidence of, and mortality from tetanus ${ }^{1}$. However, although prophylactic antitoxin accomplished much, it did not provide absolute protection and there were disadvantages.

In 1924 Descombey reported the preparation of a tetanus toxoid ${ }^{2}$, and in 1927 Ramon and Zoeller demonstrated that this toxoid stimulated active immunity in $\operatorname{man}^{3}$. In collaboration with Wellcome Research Laboratories, Boyd, at the Royal Army Medical College, confirmed the discovery and determined an optimal two-dose regimen ${ }^{4}$. Consequently, active immunisation against tetanus was introduced as official policy of the British Army in 1938, although acceptance was voluntary ${ }^{5}$. Significant evidence for the efficacy of tetanus vaccine was provided by wounded vaccinees in the war of $1939-45^{5}$, although passive immunisation also was used for wound prophylaxis. An annual reinforcing dose of toxoid was introduced in November $1942^{6}$. Active immunisation was discontinued in 1945 only to be resumed in 1949 . Current tetanus prophylaxis ${ }^{7}$ originates from the comprehensive studies by $\mathrm{Sachs}^{8}$ in which emphasis was laid on active rather than passive immunisation.

A combined vaccine against Typhoid, Paratyphoid A and $B$, and Tetanus (TABT) was first described by Ramon and Zoeller ${ }^{3}$; the tetanus antitoxin response being found to be greater to toxoid in combination than to toxoid alone. This enhanced response was confirmed later by Maclean and Holt during vaccination of hospital staff in $1940^{9}$. The RAF introduced a phenolised TABT vaccine in 1949, and this was adopted by the Army in 1953. TABT, manufactured by the David Bruce Laboratories $(\mathrm{DBL})^{10}$, has been in general use since 1959 for both primary intradermal immunisation ${ }^{11}$ and 3-yearly reinforcement of Service personnel. The clinical protection effected by this vaccine appears to be excellent and the incidence of general and local reaction has been remarkably low ${ }^{12,13}$.

The success of tetanus prophylaxis in the Armed Forces had repercussions in civilian practice, and active immunisation was introduced into the UK as part of primary immunisation of infants in 1961 and for universal use in the treatment of wounds in 1970. Tetanus has been virtually eliminated from the child population in Britain, but some elderly adults remain at risk.
In 1988, the production at DBL of vaccines for TriService use: TABT, TAB (without Tetanus) Plague and: Cholera, was discontinued. However, this year sees the adoption of Adsorbed Tetanus Vaccine BP, Typhoido Vaccine BP (monovalent) and Cholera Vaccine BP음 among the radical changes occurring in Service $\frac{\bar{\omega}}{\bar{T}}$ immunisation policy ${ }^{14}$. Adsorbed Tetanus Vaccine BP $\widehat{\otimes}$ is fundamentally different from TABT: the toxoid content is seven-times greater, it is adsorbed on to ${ }^{\text {s }}$ aluminium hydroxide, it is routinely inoculated intra- $\vec{O}$ muscularly and ordinarily should not be given more $\vec{\overrightarrow{ }}$ often than once every ten years ${ }^{15}$.

Faithfull-Davies et al., (this issue) have provided $\vec{\nabla}$ serological evidence that during 30 years of use, TABT 3 has maintained a protective level of tetanus antitoxin in ? the blood of Service personnel of all ages. Similarly, all $\vec{\omega}$ individuals tested had protective levels of antitoxin at ${ }^{\prime}$ entry. These levels are commensurate with age-related $\varphi$ antitoxin titres defined in recent UK studies ${ }^{16,17}$.

The prophylactic efficacy of a completed primary응 course of tetanus toxoid is established, with evidendethat adsorbed toxoid produces higher and moge prolonged antitoxin titres than plain toxoid ${ }^{18,19}$. Aftorof primary immunisation, serum antitoxin levels declipe continuously ${ }^{20}$. However, immunological recall ce्n occur up to 30 years after primary vaccination; ome reinforcing dose of adsorbed toxoid being sufficient $\$ 0$. induce long lasting protective levels of antitoxin. Recent studies have indicated that the greater the interval between primary and re-vaccination, the slower $\overrightarrow{0}$ is the rise in antitoxin level ${ }^{21}$; this finding has been proposed as one explanation for the development of tetanus after trauma in previously vaccinated $\stackrel{2}{\vec{F}}$ individuals ${ }^{22,23}$. These observations emphasise the need $\frac{0}{3}$ for re-vaccination in order to maintain solid immunity in $\overrightarrow{ }$ the later life of each individual.

The recommendations for re-vaccination regimens vary between countries, are often complicated and dosage intervals range from $5-20$ years $^{7,24,25}$. In the UK, routine re-vaccination is recommended on entering and leaving school and 10 yearly thereafter, with special indications for tetanus-prone wounds ${ }^{15}$.

However, no wound should be considered free from potential infection with Clostridium tetani. The majority of tetanus cases follow minor wounds, to the extremities $\delta$ associated with agricultural injury or sport ${ }^{23,26}$. Because $₹$ of the trivial nature of these wounds many patients doo not seek medical attention ${ }^{23,27}$. Hence tetanus cannot be totally eliminated even by correctly administeredo prophylaxis after injury. Service personnel are at increased occupational risk of infection. New recruits, $\Omega$ particularly those in field units, often sustain minor ${ }^{N}$ 
injuries during training and sport, after which tetanus revaccination is frequently given. When formulating a tetanus vaccination policy the risks of hyperimmunisation must be considered. Excessive frequency of tetanus re-vaccination incurs unnecessary expense and has produced antitoxin levels of more than 40 times that required for protection ${ }^{28}$.Such high levels are associated with adverse reactions. These are mostly local and delayed, but rarely severe reaction including anaphylactic shock may occur. Therefore adoption of the present Service tetanus policy ${ }^{7}$ for Adsorbed Tetanus Toxoid BP could result in unacceptable numbers of adverse reactions and so may prejudice acceptance of tetanas immunisation by serving personnel.

Under the current UK tetanus vaccination policy ${ }^{15}$ recruits should have received at least a complete primary course, with re-vaccination on entering and leaving school. The probablity that they will all possess serum antitoxin levels above the accepted minimal protective level (Faithfull-Davies et $a l$ ) indicates that a single dose of toxoid on entry will be sufficient to maintain protection (Strategy 2).

It is intended to extend this study to determine antitoxin levels on entry for a further 1000 recruits (Strategy 3). Thereafter, it is proposed that both immune new recruits and serving personnel will convert to a routine reinforcing dose every 5 years, until 35 years of age. After this, re-vaccination will be undertaken every 10 years. This regimen obviates the need to depend upon emergency boosters after trauma because of uncertainty regarding the immune status of the individual. An integral part of this new policy will be the notification of adverse reactions after re-vaccination, and accurate recording of immunisation history so that unnecessary re-vaccination may be avoided.

The pervasive tetanus bacillus is, and will remain, ineluctable but the eradication of the terrifying disease that it causes requires nothing more than the conscientious application of the methods of immunoprophylaxis that have long been to hand.

\section{REFERENCES}

1. Official History of War: Medical Service Pathology 1922. Chapter VII, Tetanus in its Statisical Aspects.

2. DescombeY P. L'Anatoxine Tetanique.C $R$ Soc Biol. 1924; 91: 239-241.

3. Ramon G and Zoeller C. Anatoxine Tetanique et l'Immunization active de l'Homme vis-a-vis du Tetanus. Ann Inst Past 1927; 41: 803-833.

4. BoYD J S K. Active Immunisation against Tetanus. J Army Med Corps 1938; 70: 289-307.
5. BoYD J S K. Tetanus in the African and European Theatres of War. Lancet 1946; 1: 113-119.

6. Evans D G. Active Immunisation against Tetanus. Lancet 1941; 11: 628 .

7. Ministry of Defence. Memorandum on Immunological Procedures. HMSO 1968.

8. SACHS A. Modern views on the prevention of Tetanus in the wounded. Proc Roy Soc Med 1952; 45: 641-656.

9. MACLEAN I H and HOLT L B. Combined Immunisation with Tetanus Toxoid and TAB. Lancet 1940; 11: 581-583.

10. NoBle J E. The David Bruce Laboratories 25th Anniversary. J R Army Med Corps 1967; 113: 208-212.

11. BARR M, SAYerS M H P, and STAMM W P. Intradermal TABT vaccine for Immunisation against enteric: Lancet 1959; 1: 816-817.

12. NoBle J E. Reactions to intradermal TABT and TAB vaccines. JR Army Med Corps 1963; 109: 178-180.

13. Ministry of Defence. Information on file.

14. EDITORIAL. The changing face of vaccination. $J \boldsymbol{R}$ Army Med Corps 1988; 134: 117-118.

15. DHSS. Joint Committee on Vaccination and Immunisation. Immunisation against Infectious Disease. HMSO London 1988.

16. JONES A E. et al. Adverse reactions in adolescents to reinforcing doses of plain and adsorbed tetanus vaccines. Community Medicine 1985; 7: 99-106.

17. Chikhani C G and Kumar K. Tetanus booster every $5 \frac{5}{2}$ years: an unnecessary routine? Archives of Emergencyon Medicine 1988; 5: 4-11.

18. White W G. et al. Duration of immunity after active immunisation against tetanus. Lancet 1969; 11: 95-96.

19. BAINTON D. et al. Immunity of children to diphtheria tetanus and poliomyelitus. $B r$ Med $J$ 1979; 1: 854-857.

20. Simonsen O, KJELDSEN K and Heron I. Immunity to tetanus and effect of re-vaccination 25-30 years aftero primary vaccination. Lancet 1984; 11: 1240-1242.

21. SIMONSEN O. et al. Re-vaccination against tetanus 17 to 20 years after primary vaccination: Kinetics of Antibod Response. J Trauma 1987; 27: 1358-1361.

22. LA FORCE M F, YOUNG L S and BenNET J V. Tetanus in the United States (1965-1966). N Engl J Med 1969; 280: 569-574.

23. EDMONDSON R $\mathbf{S}$ and Flowers $\mathbf{M} \mathbf{W}$. Intensive care in Tetanus: management, complications and mortality in 100 cases. Br Med J 1979; 1: 1401-1404.

24. Smith J W G, Laurence D R and Evans D G. Prevention of tetanus in the wounded. Br Med J 1975; 3: 453-455.

25. SIMONSEN O. et al. Evaluation of vaccination requirements to secure continuous antitoxin immunity to tetanus. Vaccine 1987 ; 5: 115-122.

26. ATRAKCHI S A and Wilson D H. Who is likely to get tetanus? Br Med J 1977; 1: 179.

27. BowEN V. et al. Tetanus - a continuing problem in minor injuries. Can J Surg. 1988; 31: 7-9.

28. EDSALL G. et al. Excessive use of tetanus toxoid boosters JAMA 1967; 202: 111-113.

\section{ERRATUM}

The National Confidential Enquiry into Perioperative Deaths (NCEPOD) commenced on 1st January 1989 and not 1988 as stated in the last issue.

(Editorial J R Army Med Corps 1989; 135 2: 41.) 